\title{
El transporte de pasajeros por carretera en Boyacá (Colombia): sociedades, devenir e instituciones, $1930-1965^{1}$
}

Doi: 10.25100/hye.v14i50.6487

Artículo recibido: 22-05-2017 | Artículo aceptado: 06-03-2018

\section{Yenniffer Camargo Bonilla}

Licenciada en Ciencias sociales por la Universidad Pedagógica y Tecnológica de Colombia, (Colombia). Maestra en Historia (opc. historia de América) por el Instituto de Investigaciones Históricas de la Universidad Michoacana de San Nicolás de Hidalgo, (México). Candidata a doctor en Historia (historia económica) por convenio de doble titulación entre la Universidad Autónoma de Zacatecas y la Universidad de la República, (Uruguay). Pertenece al Semillero de investigación en los grupos Asociación Centro de Estudios Regionales REGION y Grupo Interdisciplinario de Investigaciones Arqueológicas e Históricas de la Universidad Pedagógica y Tecnológica de Colombia. Última Publicación: Reseña del libro "Oro y plata en los inicios de la economía global: de las minas a la moneda" de Antonio Ibarra y Bernd Hausberger, en Tzintzun. Revista de Estudios Históricos, núm. 64, juliodiciembre 2016. Correo eclectrónico: yenis3033@gmail.com

Forma de citar este artículo: Camargo Bonilla, Yenniffer. "El transporte de pasajeros por carretera en Boyacá (Colombia): sociedades, devenir e instituciones, 1930-1965”. Historia y Espacio, vol. 14, n 50 (2018): 53-84. Doi: 10.25100/hye.v14i50.6487.

1 Artículo de investigación. 


\section{El transporte de pasajeros por carretera en Boyacá (Colombia): sociedades, devenir e instituciones, 1930-1965}

Resumen: El artículo analiza los orígenes, la operatividad y los cambios del transporte de pasajeros en Boyacá. Para ello se incluyeron tres factores causales que permitieron explicar su funcionalidad y expansión en la región: primero, la configuración de la red vial que condicionó el establecimiento de rutas y zonas de servicio; segundo, el contexto socioeconómico del departamento en beneficio o detrimento de la formación de compañías vinculadas al sector; y por último, las cualidades del tejido productivo local como demandante para la movilidad poblacional. Además de la intervención institucional del Gobierno nacional en su regulación y organización como un rubro económico importante desde mediados de la pasada centuria. El estudio se elaboró a partir de fuentes notariales y hemerografía local y oficial, que dan cuenta de los aspectos señalados y muestran cómo fue el proceso de consolidación del transporte automotor dentro del escenario socioeconómico boyacense y cuáles fueron sus particularidades.

Palabras clave: Boyacá, empresas, instituciones, transporte de pasajeros

\section{The Transportation of Passengers by Road in Boyacá (Colombia): Companies, Development and Institutions, 1930-1965}

Abstract: The article aims to analyze the origins, operations and changes of the passenger transport in Boyacá, through three causal factors that allowed to explain its functionality and expansion in the region, first, the configuration of the road network that conditioned the establishment of routes and service areas, second, the socioeconomic context of the department in benefit or detriment of the Formation of companies linked to the sector, and finally, the qualities of the local productive fabric as a demander for population mobility. It's important to note the institutional intervention of the national government in its regulation and organization as an important economic item since the middle of the last century, for that reason this study was made investigating in notarial sources and local or official hemerography that give account of the indicated aspects and show how the process of consolidation of the motorcar was within the boyacense socioeconomic scenario with his peculiarities.

Keywords: Boyacá, Companies, Institutions, Passenger Transport. 


\section{Yenniffer Camargo Bonilla}

\section{El transporte de pasajeros por carretera en Boyacá (Colombia): sociedades, devenir e instituciones, 1930-1965}

\section{Introducción}

Boyacá se ha caracterizado por ser un departamento predominantemente agrícola, cuya economía depende de la variedad de recursos naturales y minerales existentes debido a la presencia de diferentes pisos bioclimáticos que han permitido su aprovechamiento y explotación de recursos naturales y minerales. Los señalamientos de Fals Borda respecto de la producción de su espacio, del arraigo de su población, y de su tardía vinculación a procesos de modernización y apertura a las tecnologías, que para principios del siglo XX ya se incorporaban en otras regiones, es una visión aproximada a la realidad histórica de aquel entonces².

Por ende, la distribución de los distintos recursos a lo largo del territorio ha determinado la especialización del trabajo en las provincias que lo conforman, es decir, mientras unas están dedicadas a la ganadería, otras explotan hierro, carbón y los diversos yacimientos que la población encuentra próximos a su vivienda. Su ubicación en la cordillera oriental es causante de la dinámica interna y de la emersión de distintos sectores como la industria, el turismo y la producción artesanal que se han transformado en nuevas formas de vida y sustento.

2 Orlando Fals Borda, El hombre y la tierra en Boyacá: bases sociológicas e históricas para una reforma agraria (Bogotá: Universidad Pedagógica y Tecnológica de Colombia, 2006), 242. 
Paralelo al entorno rural boyacense, se constituyeron a principios del siglo XX diversos proyectos económicos que se pueden considerar como los primeros intentos empresariales; los cuales se centraron en la dotación de servicios públicos como teléfonos, transportes, educación y sistema de finanzas que fueron objetos de inversión privada, y cuyo objetivo era comunicar e integrar el mercado regional; a su vez buscaban la modernización de las ciudades y la formación de espacios de sociabilidad que reforzaran el papel de las élites locales ${ }^{3}$. Sin embargo, se ha notado que muchos de estos procesos de industrialización en torno a pequeñas fábricas manufactureras y de producción de bienes intermedios o de consumo directo que se constituyeron desde finales del siglo XIX, y cuyo impacto es considerable tanto para la región como para el país, no han sido objeto de la investigación histórica, social y económica.

Asimismo, la actividad comercial y la creación de empresas importadorasexportadoras encargadas de la distribución y el consumo de mercancías fueron importantes, en la medida que fortalecían las relaciones con el espacio nacional y retenían mano de obra. No obstante, la realidad de estas compañías estuvo ligada a inversiones reducidas y a una escasa expansión fuera del mercado local, a diferencia de industrias y empresas de otros departamentos proyectadas para su crecimiento nacional ${ }^{4}$.

El desempeño económico de Boyacá se vio influenciado por la apertura de políticas económicas, como el modelo de sustitución de importaciones, que incentivaron la acumulación de capital privado y social, mientras se fomentaba la construcción de viviendas, la planeación de ciudades y la constitución de fábricas más tecnificadas e innovadoras ${ }^{5}$. La primera industria moderna del departamento fue Acerías Paz del Río, constituida en los años cincuenta luego del hallazgo de vetas de carbón, hierro y caliza alrededor de la provincia de Sugamuxi, las cuales también fueron utilizadas para la apertura de la electrificadora de Boyacá en 1964, que abasteció las demandas de energía en los centros urbanos y aseguró a las fábricas un trabajo continuo.

Además de los campos siderúrgico y de servicios, se establecieron industrias de licores, bebidas, procesadoras de alimentos y ladrilleras en Duitama y

3 Olga Acuña Rodríguez, "Aproximaciones a la historia empresarial de Boyacá (Colombia), 1900-1930”, Historielo: Revista de Historia Regional y Local vol. 6, núm. 12 (Universidad Nacional de Colombia, 2014): 4-5.

4 Ibíd., 6-7.

5 José Antonio Ocampo, “La consolidación del capitalismo moderno”, en Historia económica de Colombia, comp. José Antonio Ocampo (Bogotá: Siglo XXI editores, 1987). 
Sogamoso, ciudades que se convirtieron en centros empresariales. Carolina Barreto explica que su trascendencia se remite a las condiciones demográficas, infraestructura, obras públicas y el dinamismo económico que tenían en otros sectores. En este sentido, dichas localidades tenían el mayor número de habitantes, contaban con experiencia en la fabricación de cervezas, la producción harinera, el comercio ganadero y estaban conectadas por vías terrestres con Bogotá, Cúcuta y Bucaramanga ${ }^{6}$.

El escenario económico boyacense era favorable para el establecimiento del transporte automotor, tanto de pasajeros como de carga, en la medida que la demanda propiciada por la producción agrícola local, la creciente expansión de la industria y, por ende, de mano de obra vinculada a esta, y el acceso carretero hacia zonas apartadas de la realidad regional incrementaron los niveles de migración del campo a los principales centros urbanos, lo cual posibilitó el aumento paulatino de empresas y rutas adscritas a la operatividad de dicha actividad.

Además de ser Boyacá el segundo departamento con mayor densidad de red vial para 1960, en razón a la insuficiencia que presentaba en materia de medios de comunicación, pues al interior de su territorio solo funcionaban dos líneas férreas, una que conectaba de forma directa a Bogotá con sus tres ciudades principales (Duitama, Tunja y Sogamoso), y otra que se dirigía hacia el departamento de Santander y cuyo trayecto cubría únicamente a su capital (Tunja) ${ }^{7}$. Tales circunstancias favorecieron y fomentaron el uso de buses, chivas y camionetas como sistema de movilidad dominante desde los años cincuenta del siglo XX en casi todas sus provincias.

Cabe señalar que tanto las condiciones socioeconómicas de Boyacá como el estado de su red de carreteras justificaron este trabajo a nivel espacial; sin embargo, la selección del transporte de pasajeros como objeto de estudio responde a la escasez de trabajos que lo aborden en cuanto al orden empresarial y a su organización interna. A pesar de ser un sector significativo para la historia económica nacional, hace falta reflejar el vínculo directo del transporte con la infraestructura vial, las obras públicas del país y la incidencia de la política

6 Carolina Barreto Bernal, Conformación del empresariado del sector siderúrgico y su papel en los procesos de modernización social, económica y administrativa, en el corredor industrial de Boyacá, 1960 - 1990 (Tesis de Doctorado, Universidad Eafit, 2014), 103-118.

7 María Teresa Ramírez y Álvaro Pachón, La infraestructura del transporte en Colombia (Bogotá, Colombia: Banco de la República, 2006). 
gubernamental para su desenvolvimiento ${ }^{8}$. De esta manera, el artículo se propone demostrar cómo la expansión del sector transporte permite entender la complejidad y la dinámica del desarrollo económico de un espacio regional, a tal grado, que se plantea la conformación de un tejido productivo local y empresarial ${ }^{9}$.

Ahora bien, situar esta interrogante en el período planteado permite dar cuenta de la creación de la primera empresa de transporte en 1930, al igual que de los vínculos de las sociedades de mayor importancia regional con el marco normativo e institucional que facilitó el sostenimiento de sociedades de envergadura nacional, las cuales fueron adquiriendo a pequeñas compañías imposibilitadas para competir y funcionar bajo el orden legal establecido.

Igualmente, con la pregunta formulada se pretende reafirmar que la configuración del transporte de pasajeros en Boyacá impulsó procesos de modernización e integración socioeconómica a nivel regional y nacional, en tanto el establecimiento de nuevas rutas permitió la apertura de mercados locales, la conformación de espacios de sociabilidad y la vinculación entre el mundo rural y el espacio urbano. No obstante, se aseverará que uno de los determinantes en los espacios de servicio y el devenir versátil de la actividad fue la acción institucional del gobierno.

Para corroborar la hipótesis y dar respuesta a la inquietud central del artículo, se hizo uso del Diario Oficial, periódico oficial del país, el cual se complementó con fuentes notariales y algunas notas de diarios nacionales y locales; documentación que en conjunto permitió contrastar el marco institucional y normativo con los instrumentos de operación de las empresas, así como la autonomía de estas para vincularse a la actividad y, con ello, tener mayor rentabilidad del transporte como negocio. Aunque la riqueza de las fuentes es pertinente para los objetivos del presente trabajo, se limitan en cuanto al papel de actores empresariales y políticos, y realmente dicen poco sobre el actuar de los transportistas y sus vínculos con el poder político regional.

8 Sebastián Villarreal y Darío Ortiz, "Transporte y mercado interno en Colombia: una contribución a un debate hasta ahora desconocido, 1928-1950”, Tiempo y Economía vol.3, núm.1 (Universidad Jorge Tadeo Lozano, 2016): 83-107.

9 Esta interrogante coadyuva, en primer lugar, a explicar la incorporación de grupos empresariales dentro de procesos económicos de la región y, en segundo lugar, a resolver de cierto modo una de las ausencias en la historiografía económica. Adolfo Meisel Roca, "Los estudios sobre historia económica de Colombia a partir de 1990: principales temáticas y aportes”, Cuadernos de historia económica y empresarial, núm.13 (Bogotá: Banco de la República, 2005): $4-42$. 
El trabajo está estructurado en cuatro apartados que condensan los elementos planteados: en el primero se esboza tanto el enfoque metodológico como las categorías que sirven como hilo conductor del mismo; en el segundo se describe el panorama institucional de la actividad a partir de sus primeros órganos y normativas; en el tercero se exponen consideraciones sobre las tarifas y zonas de servicio, prestando interés particularmente a la línea principal de Boyacá (carretera central del Norte), y finalmente se evidencian ciertos nexos administrativos, de recursos y operatividad en la estructura de las empresas pertenecientes al sector.

\section{Perspectiva de análisis y marco conceptual}

Inicialmente el trabajo estaba encaminado al campo empresarial; no obstante, las fuentes y la estructura del mismo lo redirigió hacia cuestiones políticas, económicas y sociales que se aglomeraron bajo dos amplias ramas de la historiografía: por un lado, la historia del transporte y las comunicaciones y, por otro, el ya mencionado enfoque empresarial. El primero se fundamentó en la perspectiva de María Teresa Ramírez, quien ha articulado la intervención gubernamental y el estado de las obras públicas como posibilitadores o limitantes para la configuración y expansión de las redes de movilidad ${ }^{10}$. En Colombia este enfoque ha permitido reconstruir y explicar las transformaciones sociales que se originaron a partir de cambios dentro del sistema económico, la innovación tecnológica y la aparición o fortalecimiento de nuevos medios de comunicación que llevan a la metamorfosis de la cotidianidad colectiva e individual.

La historia del transporte y las comunicaciones se transformó en elemento imprescindible, no solo para exponer el contexto, sino para entender la inclusión de sus compañías conforme a las condiciones socioeconómicas y políticas de una región o un espacio. Por consiguiente, se dedicó una parte del trabajo a dos bloques temáticos: el crecimiento de las rutas o espacios de servicio, y la institucionalidad que vigilaba y controlaba la actividad en cuanto a tarifas y operatividad.

${ }^{10}$ Ramírez y Pachón, La infraestructura de transporte en Colombia, 548; María Teresa Ramírez, "Efectos de eslabonamiento de la infraestructura de transporte sobre la economía colombiana: 1900-1950", en Economía colombiana del siglo XX: un análisis cuantitativo, eds. James Robinson y Miguel Urrutia (Bogotá: Banco de la República y Fondo de Cultura Económica, 2007), 383-459; Hadi Salehi Esfahani y María Teresa Ramírez, "Intitutions, Infrastructure and Economic Growth”, Forthcoming in Journal of Development Economics, 70 (IISES, 2003). 
En razón a las pocas investigaciones sobre esta temática fue necesario plantear una propuesta metodológica que condensa los señalamientos de Ramírez con la estructura misma de la investigación y la postura de Gustavo Garza, quien define la actividad transportadora dentro del sector servicios, clasificándola como un elemento necesario para el incremento y desarrollo empresarial, al igual que un factor determinante e impulsor de la infraestructura y las obras públicas. Aunque no hay un consenso para definir la categoría servicios, se refieren algunas características homogéneas que permiten su identificación: la utilidad para el consumidor, el uso de la industria manufacturera, el hecho que sean gratuitos o generen un costo, y el vínculo que se mantiene entre el productor-comprador independientemente de su consumo inmediato o duradero ${ }^{11}$.

Para el caso del transporte de pasajeros se encontraron ciertas cualidades antes señaladas, por ejemplo: el beneficio socioeconómico visto desde los procesos migratorios y la emersión del comercio; la relación directa con el sector automotriz como proveedor de insumos y redes de negocios; la atribución de una tarifa para su empleo; y la responsabilidad exigida al empresario frente al usuario en cuanto a su equipaje, seguridad y comodidad.

Con base en lo anterior, fue imprescindible estudiar las políticas públicas (inicios, modificaciones y revocaciones) que determinaron la forma de funcionar de las empresas, los costos, sanciones, registros e incluso balances financieros del sector. Esto sin dejar de lado las pretensiones institucionales y políticas que tuvieron tanto el poder ejecutivo como los empresarios en la regulación, control y vigilancia de la actividad. En este sentido, se valoró hasta dónde la normativa se cumplió a cabalidad en beneficio o detrimento del transporte.

Aunado a ello, se utilizó la noción de tejido productivo local, con la cual se pretendió corroborar y plantear una de las conclusiones centrales que explica el escenario económico regional de Boyacá, donde se integran tres aspectos claves: "a) interrelación generada y sostenida entre productores y empresas dentro del mismo ámbito regional, b) constante cooperación entre productores, c) vínculos económicos, familiares y organizacionales que establecen los

${ }^{11}$ Gustavo Garza, “La revolución macroeconómica del sector servicios”, en Laeconomía mexicana en 19 miradas, coord. Daniel Flores Curiel, María Lourdes Treviño Villarreal y Jorge Noel Valero Gil (México D. F.: Universidad Autónoma de Nuevo León, Porrúa, 2009), 361-391. 
agentes productivos para la diversificación de actividades"12. Factores que dentro del objeto de estudio fueron vistos, por un lado, en la incidencia y vínculo estratégico sostenidos con Bogotá y los Santanderes y, por otro, en la interacción del transporte como multiplicador, dinamizador o dependiente de las actividades económicas predominantes de Boyacá.

Igualmente, se justificó, desde los planteamientos de Dennis Maillat, la necesidad de abordar los procesos de continuidad o ruptura a partir de espacios regionales que empezaron a considerarse por la historiografía económica como estructuras activas de transformación, en tanto sus sistemas productivos locales se han convertido en causales de redes de producción, transformaciones sociales e innovación económica, que manifiestan la constante interrelación entre los agentes económicos, las actividades, el mercado y las políticas institucionales reguladoras dentro de un entorno ${ }^{13}$. Lo sugerente de su propuesta es el ajuste que tiene con la operatividad del transporte de pasajeros en Boyacá, donde se conformaron sociedades pequeñas de corta y mediana duración que dieron cabida a líneas de servicio amplias para el devenir económico de otros sectores, así como para el proceso de integración e intercambio social.

En cuanto al enfoque empresarial, se utilizaron algunos referentes conceptuales y metodológicos del mismo, que realizan, a partir de la figura del empresario o la empresa, un análisis del contexto institucional, social y político. Pues la actividad empresarial, ya sea de manera planificada u organizacional, revela las modificaciones a nivel técnico, las características del entorno geográfico inmediato y las condiciones socioculturales de un grupo poblacional ${ }^{14}$. De igual forma, es la historia empresarial como señala Joseph Schumpeter, un campo de estudio que cada vez más evidencia los procesos de desarrollo y las dinámicas económicas de una región o espacio ${ }^{15}$.

12 Mario Cerutti, "Crisis y reconvención del tejido productivo en un espacio regional del norte de México: La Laguna (1875-1975)”, Revista Investigaciones de Historia Económica, 10 (España: Asociación Española de Historia Económica, 2008): 97-128.

${ }^{13}$ Denis Maillat, "Sistemas productivos locales y entornos innovadores", en Redes de empresas y desarrollo local: competencia y cooperación en los sistemas productivos locales (París, Francia: OCDE: 1999), 77-79.

${ }^{14}$ Carlos Marichal, “Introducción”, en Historia de las grandes empresas en México (1850-1950), comp. Mario Cerutti y Carlos Marichal (México: FCE, 1997), 9-38.

15 Joseph Schumpeter, Teoría del desenvolvimiento económico (México, FCE, 2012), 255. 


\section{Marcos institucionales en la movilidad poblacional boyacense}

La operatividad de las empresas de transporte, ya sean de carga o pasajeros, ha estado sujeta a las políticas promulgadas desde el poder ejecutivo en compañía de los entes encargados de controlar y vigilar tanto la conformación, licencia y funcionamiento de las empresas, como su impacto económico a nivel regional. En este sentido, se pretende analizar la relación entre las instituciones, la constitución de las empresas y los empresarios teniendo en cuenta la postura de Douglas North, quien señala el condicionamiento de estas a normatividades políticas y legales que regulan en muchos casos su relación con la sociedad, orden administrativo y estructura económica. Según North, las institucionesson las reglas del juego en una sociedad o, más formalmente son las limitaciones ideadas por el hombre que dan forma a la interacción humana ${ }^{16}$, es decir, las evoluciones de las sociedades han dependido de los cambios políticos e institucionales que marcaron el devenir de la economía política en los países, las colectividades, e incluso, los individuos.

En efecto, las limitaciones formales generadas por las leyes estatutarias, los reglamentos y los derechos proclamados por los gobernantes respecto a las actividades económicas fueron medios de efectividad o coerción para los empresarios. Por otra parte, el trascurrir del tiempo evidenció que conforme los organismos iban cambiando a nivel de dependencias, nombres, atribuciones y estructura de oficios, se definió gran parte de las transformaciones en relación a disposiciones públicas y exigencias dentro de las economías. En razón a lo anterior, se expondrán a nivel general las modificaciones existentes respecto a las leyes y medidas que rigieron el transporte público antes y después de la creación de la Dirección Nacional de Transportes en 1943, de tal forma que se señalen las condiciones requeridas para el reconocimiento de las empresas, las obligaciones de las mismas con el Estado, y el establecimiento y aprobación de tarifas de acuerdo a la magnitud y rango de operación de la compañía.

Las instituciones colombianas, en teoría, han sido planteadas, tal como señala el modelo neoinstitucional, a partir de las convenciones informales (costumbres o códigos de conducta que se modifican por la experiencia), las normas formales (reglas políticas y económicas), y los procedimientos de cumplimiento obligatorio. No obstante, las relaciones entre los estamentos y la manera en que se concibe la actividad empresarial han estado influenciadas por necesidades de recompensa, es decir, el bienestar relativo, la riqueza y el

${ }^{16}$ Douglas North, Instituciones, cambio institucional y desempeño económico (México D. F.: Fondo de Cultura Económica, 1995), 14-19. 
poder del empresario y la fuerza coercitiva del Estado, que de acuerdo a los incentivos o ventajas regulan las medidas, contratos, concesiones y legislación en favor de sus intereses ${ }^{17}$. En este sentido, el bienestar social que podría generar el cambio económico respecto a un sector empresarial (en particular el transporte), estuvo determinado por clientelismo y grados de representatividad supeditados al hombre de negocios.

Al parecer, antes de los años cuarenta el control e intervención sobre el transporte automotor y las empresas oficiales o privadas que ofrecían dicho servicio era mínimo. La Comisión Nacional de Transportes y Tarifas, creada desde 1927, se preocupaba más por expedir ordenanzas que regularan el tránsito de los vehículos de tracción mecánica, pues de esta manera se evitaba el desorden dentro de las carreteras y se mantenía vigilado el rubro generado del impuesto de placas y matrículas de los automotores ${ }^{18}$.

Tras los efectos producidos dentro de la organización económica y fiscal del país durante la Segunda Guerra Mundial, al presidente se le otorgaron nuevas facultades respecto del fomento y la protección de las industrias nacionales. Dentro de las cuales consideró la adopción de nuevas medidas que mejoraran las condiciones de las empresas de transporte, al ser estas indispensables para el aumento de la producción y mano de obra, en cuanto al costo, rapidez y seguridad en la movilidad de mercancías y empleados. Para esto estableció el cobro de tarifas, que contemplaran unos valores mínimos exigidos para algunas rutas nacionales, y reorganizó la Comisión Nacional de Tarifas para convertirla finalmente en la Dirección Nacional de Transportes y Tarifas.

Los vínculos configurados entre el gobierno y las compañías de transporte público terrestre se observaron en los estudios de aprobación de itinerarios,

17 Daron Acemoglou, Simon Johnson y James Robinson, "Institutions as the Fundamental Cause of Long-Run Growth”, The National Bureau of Economic Research, núm. 10.481 (2004): 111.

18 Por ejemplo, la Ley 60 de 1939 estipulaba que el pase de choferes y el registro de los coches se expedían únicamente en la Dirección de Circulación y Tránsito en la cual se había inscrito por primera vez. Estos documentos permitían a los carros circular por todo el territorio nacional, pero las placas eran registradas en el municipio de dónde provenía el propietario o de asiento principal de los negocios de la compañía; su enumeración era continua según el total de autos patentados en el departamento. Con esto se acaudalaban fondos a partir del cobro de placas y el gravamen vehicular que tenían por fin arreglar las vías o caminos nacionales, Archivo General de la Nación Colombia (en adelante AGNC), Diario Oficial: Congreso de Colombia. 1939. "Ley 60 del 19 de diciembre de 1939, por la cual se dictan algunas disposiciones sobre tránsito”, 22 de diciembre. 
reglamentos y tarifas que cada una de las empresas solicitaba ante el Estado; aquellas peticiones se asignaban o rechazaban acordes con la estabilidad financiera de la sociedad y la participación que esta hiciera en el desarrollo de la industria nacional. Desde entonces la conveniencia pública e institucional era primordial y decisiva en las disposiciones políticas. La industria del transporte estuvo supeditada a la situación económica y a los beneficios que podían recibir los miembros de las gobernaciones y judicaturas, con base en la rentabilidad y crecimiento empresarial.

Si bien la instauración de dicho órgano reguló la parte operativa y empresarial de la actividad transportadora en cuanto a los deberes de las compañías y los requisitos previos exigidos para la autorización de su servicio, la industria transportadora manifestaba un continuo desorden económico, pues algunos propietarios retiraban sus vehículos de una sociedad o ruta y se afiliaban a otra sin comunicar dicho cambio a la dirección, lo que afectaba la capacidad transportadora en ciertas líneas, en las que había exceso de buses, automóviles y camionetas. Situación que motivó el estudio del cupo de las carreteras, respecto del número de empresas y el total vehículos ${ }^{19}$.

Hasta mediados de los años cuarenta el transporte continuó legislándose de acuerdo a las condiciones del mercado externo (suspensión de suministro de nuevos equipos o maquinaria) y a la obligación del Estado ante las consecuencias provocadas por la libertad que tenía la industria transportadora automotora. Por consiguiente, los intereses en las medidas se enfocaron a la protección de los empresarios y a la búsqueda de estabilidad en el servicio a través de la organización de líneas fijas, en las que las empresas debían funcionar de acuerdo con la demanda que mostraba el tráfico promedio y el límite de la capacidad transportadora por vía nacional o local. A su vez, tenían que atender a los organismos fiscalizadores sobre cobro de tarifas, pues constantemente se modificaban los precios. Finalmente, las instituciones, tal como señala Kalmanovitz para el siglo XIX, fomentaban la hegemonía económica y política de los hombres de negocios, ya que se les consideraba como figuras centrales dentro del proceso de acumulación de capital, crecimiento industrial y expansión de la economía interna ${ }^{20}$.

${ }^{19}$ AGNC, Diario Oficial: Dirección Nacional de Transportes. "Resolución N. ${ }^{\circ} 6$ del 8 de abril de 1942, por la cual se dictan algunas disposiciones sobre vehículos de transporte, afiliados a empresas públicas".

${ }^{20}$ A pesar que la afirmación de este autor se enfoca a procesos del siglo XIX, las instituciones en Colombia durante la siguiente centuria continuaron bajo acciones clientelistas, en las que 
Ante los desequilibrios en el transporte se decretó la principal normativa de este sector. La Resolución 120 del 11 de junio de 1945 ratificó el intervencionismo estatal en la actividad transportadora respecto de tres aspectos principales: infraestructura vial, industria y comercio nacional. Con esta medida se establecieron los conceptos de servicio público (de transporte de pasajeros o carga ofrecido por carretera a una población, mediante un precio y con el uso de vehículos de propiedad de los socios de una compañía), empresa de transporte automotor (actividad económicamente organizada en favor del servicio de movilidad eficaz, regular y continuo) y unidades móviles (son aquellas que se encuentran bajo administración de la empresa, ya sea, porque son de su propiedad, o se vincularon por medio de afiliados y socios; funcionan a través de contratos concedidos por la Dirección Nacional) ${ }^{21}$.

Asimismo, la Resolución 120 recogió algunas ordenanzas de años pasados en las que se decretaban las obligaciones de las compañías de transporte de pasajeros en cuanto a la variación de la capacidad transportadora, que solo podía hacerse con autorización de las oficinas correspondientes; a cumplir con los horarios e itinerarios fijados que se estipularían en los tiquetes de viaje; a efectuar los turnos otorgados a la empresa por la seccional de tarifas y transportes de su localidad; a solicitar el permiso para la venta de los vehículos, chasises y motores matriculados a $\mathrm{X}$ o $\mathrm{Y}$ empresa; a entregar un balance financiero en el que apareciera el estado de los coches y el total de utilidades, luego de establecer los gastos generales y los ingresos por vehículo o ruta. Además, se prohibía la salida de unidades sin la planilla y las cartulinas

intervenían los empresarios y las elites regionales en favor de sus intereses. Sin embargo, la relación hombres de negocios-gobierno estuvo enmarcada primordialmente en los sectores de mayor índice de productividad. Es decir, los grupos empresariales que participaban en las decisiones respecto de los cambios en la política pública fueron aquellos que lograron a través de su industria conformar redes de poder y ascendencia electoral. No obstante, el caso de los empresarios transportadores en Boyacá tuvo algunas particularidades, pues su carácter de pequeña y mediana inversión no influyó en amplias magnitudes dentro de las ordenanzas o reglamentos del transporte. Lo anterior no implica que estuvieran excluidos de las decisiones gubernamentales; por el contrario, había representantes de las empresas y trabajadores que eran elegidos por el ejecutivo, que de manera centralizada disponía los participantes dentro de las mesas de discusión. Salomón Kalmanovitz, Las instituciones y el desarrollo económico en Colombia (Bogotá: Editorial Norma, 2001), 92.

${ }^{21}$ AGNC, Diario Oficial: Ministerio de Obras Públicas. "Resolución 120 del 11 de junio de 1945 , por la cual se reglamentan los servicios de transporte automotor por carreteras", Arts. $1-5$. 
entregadas por la Dirección Nacional que estatuían los horarios, líneas y precios por vía, las cuales se debían portar en los diferentes carros.

Respecto a la movilidad de personas se incluyeron los artículos 29 a 40, en los que se reglamentó lo correspondiente a los pasajeros, la actividad mixta y las planillas. En primer término, se señaló la responsabilidad de la empresa frente al cliente desde su abordaje hasta su destino. En segundo orden, el transporte mixto se definió como la movilización de mercancías y personas dentro del mismo automotor, en aquellas rutas veredales que de manera obligatoria exigieran dicho servicio. Finalmente, las planillas o relación de pasajeros por carro era el documento que acreditaba el funcionamiento legal de las empresas ante las oficinas seccionales de transporte.

En conclusión, la legislación promulgada hasta entrada la década de los cincuenta no provocó grandes cambios en la organización empresarial del transporte automotor de pasajeros; contradictoriamente, continuó la polarización de los empresarios, el desorden en materia de rutas y la ausencia de entidades oficiales fuertes que intervinieran a favor de coyunturas y procesos nuevos en la actividad transportadora.

\section{Plan tarifario y redes de servicio del transporte de pasajeros en Boyacá}

El orden legislativo y corporativo condujo a su vez a la revisión de las zonas de servicio, lo cual no puede solo enunciarse de manera tajante sin una explicación, al menos, del porqué de la importancia y la centralidad de cierta línea o espacio para las empresas, los usuarios y el gobierno en general; por tanto, las consideraciones que se plantearon obedecen al contexto económico e histórico del objeto de estudio. En suma, lo señalado alrededor de la actividad transportadora, y todo lo derivado de ella, se interpretaron desde la teoría de interacciones generales que sustenta la localización o ubicación de los servicios acorde al papel de los empresarios, la política e instituciones gubernativas y la demanda social ${ }^{22}$.

Bajo esta perspectiva, la configuración del sistema institucional y las medidas de control establecidas respecto a la actividad transportadora determinaron las líneas por donde se llevaría a cabo el servicio de pasajeros. Estas, en numerosas ocasiones, se fijaban en las licencias de funcionamiento conferidas por el Ministerio de Obras Públicas a las distintas compañías que solicitaban su registro legal; no obstante, algunas veces se disponían las rutas

22 David Prince y Alasdair Blair, The Changing Geography of the Service Sector (Londres: Belhaven Press, 1989). 
alrededor de la carretera principal del departamento y la extensión de la red vial a nivel regional.

Es decir, los espacios de prestación del servicio se definían de acuerdo al avance en infraestructura que se tenía. Para Boyacá, se encontraron múltiples resoluciones en las que se mencionaban la compañía, la cobertura de rutas, las tarifas y los itinerarios de servicio. Sin embargo, en el presente apartado solo se expondrán el régimen tarifario y el rango de operación de aquellas empresas constituidas bajo escritura o términos notariales. Pues, en el margen del periodo comprendido entre 1940 y 1955, el Ministerio y la Dirección Nacional de Transportes y Tarifas decretaron viables un sinnúmero de licencias a distintas sociedades, empero muchas de estas medidas se quedaron enunciadas en los diarios oficiales, mas nunca se cumplieron a cabalidad.

Con base en las fuentes primarias, se observó que 1940 fue el primer año en el que se aprobó, aunque con carácter provisional, los horarios, el reglamento y las tarifas para las rutas que servirían algunas empresas como la Cooperativa Colombiana de Transportes Limitada ${ }^{23}$. Esto, en razón a la reorganización que meses anteriores llevó a cabo la Comisión Nacional, la cual en conjunto con el Poder Ejecutivo, se preocupó por atenuar las consecuencias de la Segunda Guerra Mundial y, por consiguiente, propuso como medida de fomento y crecimiento económico interno el establecimiento de tarifas férreas, fluviales y terrestres, en las que se articularan las necesidades industriales, sociales y las exigencias empresariales de los sistemas de transporte. Las compañías de servicio público solicitaban la vigencia de las rutas y los nuevos costos de la actividad ante este organismo, que finalmente decidía la asignación o el rechazo de las peticiones ${ }^{24}$. Después de la asignación de nuevas funciones,

${ }^{23}$ En principio los edictos promulgados por el Gobierno nacional en torno a las licencias de funcionamiento se estructuraban bajo el mismo modelo; es decir, contemplaban la normatividad por la cual se orientaban las empresas; haciendo referencia a las obligaciones de aquellas frente a las horas de salida, la carga de pasajeros en agencias intermedias, la ubicación de los usuarios en el vehículo, y la entrega de tiquetes al conductor al finalizar el viaje. De igual manera, se determinaba los horarios de la ruta en cuanto al lugar de destino y espacio de salida, por ejemplo en la línea Bogotá - Tunja los buses se despachaban a las 12 y 30 p. $\mathrm{m}$. También se mencionaba los costos de viaje que hasta entonces no superaban seis pesos, a excepción de la ruta Bogotá a Cúcuta que en su momento era la más larga. AGNC, Diario oficial: Poder Ejecutivo. "Resolución N. ${ }^{\circ} 1.074$ del 23 de julio de 1940, por la cual se aprueban el reglamento, los horarios y las tarifas de la Cooperativa Colombiana de Transportes".

${ }^{24}$ AGNC, Diario Oficial: Poder Ejecutivo. "Resolución N. ${ }^{\circ} 485$ del 8 de marzo de 1940, por la cual se reorganiza la Comisión Nacional de Tarifas”, Arts. 2-3. 
la Comisión realizó algunas sesiones durante julio y agosto para evaluar las demandas presentadas.

En Boyacá durante este año se concedieron licencias de funcionamiento a las empresas Busexpreso, La Garantía, Cooperativa Colombiana de Transportes, Garagoa Limitada y Compañía Ferreira, constituidas por escritura notarial entre 1935 y 1938, sin estipular con claridad las rutas que servirían. Las cinco sociedades anotadas, a excepción de la empresa Garagoa, contaban con oficinas en Bogotá y Tunja, de ahí que sus servicios abarcaran los municipios intermedios entre estas dos ciudades, y otros que se prolongaban de la central del Norte hasta Cúcuta (Figura 1$)^{25}$.

De lo anterior se infiere, por un lado, que las líneas de transporte dependían de la ubicación del centro de operatividad de las empresas y, por otro, que el establecimiento de las mismas fue cambiando según el contexto histórico nacional e internacional. Inicialmente, se encontró que las compañías convenían su libre tránsito por las distintas carreteras del territorio nacional. Después, algunas empresas prefirieron mencionar los caminos hacia donde se dirigían sus vehículos; las utilidades y objetos de explotación que se fijaban no dependían de las medidas transitorias del gobierno, el cual hasta ahora consideraba la industria del transporte automotor un sector libre y en expansión. Sin embargo, a inicios de la década de los cuarenta, cuando las diferentes compañías se regularon a través de la intervención estatal, muchas, sin tener aún la licencia, optaban por anotar en sus actas de constitución su dependencia de los mandatos de la Dirección Nacional de Transportes y Tarifas.

En algunas escrituras se da cuenta de lo mencionado; por ejemplo La Garantía Limitada, constituida por documento número 1.238 de 1938 de la Notaría Primera del circuito de Tunja, dejaba claro que explotaría el transporte de pasajeros en todas las carreteras nacionales del país. Mientras que en su acta de prórroga número 1.065 de 1942 de la Notaría Segunda del mismo circuito indicaba que sus líneas de servicio serían aquellas permitidas por la Dirección Nacional de Transportes y Tarifas, de esta forma evitaba problemas o rivalidades con otras sociedades ${ }^{26}$.

${ }^{25}$ AGNC, Diario Oficial: Ministerio de Obras Públicas, Resolución N. ${ }^{\circ} 1.074$ de 23 de julio, Resolución N. ${ }^{\circ} 1.082$ de 30 de julio, Resolución N. ${ }^{\circ} 1.105$ de 16 de agosto, y Resolución N. ${ }^{\circ}$ 1.124 de 5 de septiembre de 1940 , por las cuales se aprueba el reglamento, los horarios y las tarifas de la Cooperativa Colombiana de Transportes y las empresas Garagoa, Busexpreso y la Garantía Limitada, respectivamente.

${ }^{26}$ Archivo Regional de Boyacá (en adelante ARB), Notarías Primera y Segunda del Circuito de Tunja: Escritura N. ${ }^{\circ} 633$ del 23 de agosto de 1938. 
Figura 1. Espacios de servicio por la carretera central del Norte

\begin{tabular}{|c|c|c|}
\hline Empresas & Años & Ruta \\
\hline Cooperativa de Transportes La Colombiana & $1940-1941$. & \multirow{9}{*}{$\begin{array}{l}\text { Bogotá-Tunja-Duitama-Belén- } \\
\text { Santa Rosa-Santa Rosita-Soatá- } \\
\text { Málaga-Cerrito-Chitagá-Cúcuta }\end{array}$} \\
\hline Busexpreso & $\begin{array}{l}1940-1941, \\
1946-1949 .\end{array}$ & \\
\hline Empresa Ferreira & $1940,1954$. & \\
\hline Sociedad de Transportes Tundama & 1945 & \\
\hline Transportes Cúcuta Limitada & $1946-1953$ & \\
\hline Trans Bolivar Limitada & $1946-1949$ & \\
\hline Domingo Pérez H. S.A & 1946 & \\
\hline Rápido Duitama & 1947 & \\
\hline $\begin{array}{c}\text { Transportes Santander Limitada (con destino a } \\
\text { Málaga) }\end{array}$ & 1949 & \\
\hline $\begin{array}{c}\text { Cooperativa de Transportes La Colombiana } \\
\text { Busexpreso }\end{array}$ & $\begin{array}{l}1940-1941 . \\
1940-1941, \\
1946-1949 .\end{array}$ & \multirow{4}{*}{$\begin{array}{c}\text { Bogotá-Duitama-Santa Teresa- } \\
\text { Socha. }\end{array}$} \\
\hline La Garantía Limitada & 1941 & \\
\hline Transporte Flota Valderrama & $1948-1953$ & \\
\hline Transportes Cúcuta Limitada & 1953 & \\
\hline Cooperativa de Transportes La Colombiana & 1940. & \multirow[t]{2}{*}{ Bogotá-Duitama-Cocuy } \\
\hline Transportes Norte S. A. & 1949 & \\
\hline $\begin{array}{c}\text { Empresa Ferreira (espacio de destino es Duitama) } \\
\text { Cooperativa de Transportes La Colombiana }\end{array}$ & $\begin{array}{c}1941 . \\
1940-1941\end{array}$ & \multirow{6}{*}{$\begin{array}{l}\text { Bogotá-T unja-Paipa-Duitama- } \\
\text { Sogamoso }\end{array}$} \\
\hline La Garantía Limitada & 1941 & \\
\hline Sociedad de Transportes Tundama & 1945 & \\
\hline E1 Rápido Boyacense Limitada & 1949 & \\
\hline Flota de Los Andes & 1953 & \\
\hline Transportes Cúcuta Limitada & 1953 & \\
\hline Cooperativa de Transportes La Colombiana & 1940. & \multirow[b]{2}{*}{ Bogotá-Duitama-E1 Espino } \\
\hline Transportes Norte $\mathrm{S}$. A. & 1949 & \\
\hline La Garantía Limitada & $\begin{array}{c}1940-1941, \\
1946-1949 . \\
1941\end{array}$ & Bogotá-Duitama-Corrales \\
\hline Empresa Ferreira (lugar de llegada Belén) & 1941 & \multirow{3}{*}{$\begin{array}{c}\text { Bogotá-Duitama-Belén -Tasco- } \\
\text { Paz del Río }\end{array}$} \\
\hline La Garantía Limitada (con destino a Belén) & 1941 & \\
\hline Transportes Cúcuta Limitada & 1953 & \\
\hline
\end{tabular}

Fuente: elaboración propia con base en el Diario Oficial (1940-1953) ${ }^{27}$

${ }^{27}$ Los cuadros presentados en adelante sobre las empresas que operaban en las zonas o rutas señaladas fueron elaborados a partir de las resoluciones otorgadas por la Dirección Nacional de Tarifas, en las que se aprobaban sus licencias de funcionamiento. 
Por otra parte, en 1942, tras aprobarse la primera ordenanza que reglamentaró el transporte, se modificó tanto la documentación requerida para los permisos previos de explotación de las empresas de rutas interdepartamentales e intermunicipales como los aspectos a tener en cuenta para los cambios de tarifas. Respecto a este punto, se evidenció que la Dirección Nacional de Transportes y Tarifas incluyó, dentro del estudio de los costos del servicio automotor por carreteras, la distancia en kilómetros entre el lugar de salida y el destino, y el estado del camino por el que transitarían los vehículos. En tanto, los costos por camino se afirmaban de manera generalizada para todas las empresas que allí funcionaran.

En la Resolución 17 del 15 de mayo de 1942, mediante la prórroga otorgada por un mes para las compañías que movilizaban carga o pasajeros de Duitama a Cúcuta y ramales se visibilizaban, en primer lugar, las dificultades de adscripción de las sociedades al nuevo sistema exigido por las instituciones. En segundo lugar, las transformaciones recurrentes y continuas de las medidas, lo cual interrumpía el crecimiento constante de las compañías y, finalmente, los inconvenientes del gobierno en la instauración de ordenanzas debido al desconocimiento del sector ${ }^{28}$.

De este modo, las medidas impartidas en relación al valor de los pasajes estuvieron sujetas a los cambios en la reglamentación del transporte, pues tras la promulgación del Decreto 400 de 1942 se manifestaba que las instancias gubernamentales fijarían las tarifas acorde con las necesidades y conveniencias del gremio, las demandas del servicio y el margen de utilidad empresarial; teniendo en cuenta la opinión de la junta asesora en la que participaban representantes de los empresarios y conductores. Asimismo, se obligaba a entregar a las instituciones en papel sellado y membretado lo dispuesto para cada compañía; de esta manera la Dirección mantenía libros de registro y estadísticas por departamento ${ }^{29}$. El orden tarifario para Boyacá no variaba anualmente; existían largos periodos (de tres a cinco años) en los cuales los precios eran regulares, y algunas modificaciones halladas dependieron de las exigencias de los transportistas, lo cual no implicó que los aumentos fueran significativos.

${ }^{28}$ Véase ARB, Diario Oficial: Ministerio de Obras Públicas. "Resolución N. ${ }^{\circ} 17$ del 15 de mayo 1942, por la cual se prorroga el término a las empresas establecidas por la Carretera Central”.

${ }^{29}$ AGNC, Diario Oficial: Ministerio de Obras Públicas. "Resolución N. ${ }^{\circ} 2$ del 31 de marzo de 1942, por la cual se establece la reglamentación del transporte automotor por carreteras", Arts. 4-5. 
Las tarifas se asignaban por empresa, carretera o ruta, y se dividían en primera y segunda clase dependiendo del tipo de asiento, es decir, si estaba numerado o era libre. Ya que al vender el tiquete se estipulaba al pasajero que, según el valor pagado, tenía derecho a un cupo fijo o debía ubicarse en el sitio que estuviese desocupado conforme al orden de llegada de otras personas (cuando se accedía a las sillas con preferencias, el comprador decidía en qué parte del bus o camioneta quería ubicarse). Esta no fue la única forma de establecer los precios diferenciales en los tiquetes; en ciertos casos se instituyeron de acuerdo con el tipo de vehículo, en tanto que algunas compañías operaban dentro de la misma línea con coches y buses, puesto que al ofrecer dos modalidades de servicio se pretendía atraer mayor número de usuarios, en la medida que el coche aseguraba más comodidad, espacio y rapidez.

A partir de las ventajas que las empresas asignaban al automóvil, el costo del viaje en él era más alto para las distintas rutas independientemente de la distancia y el estado de las carreteras. Por ejemplo, en las tarifas de Chiquinquirá y ramales asignadas por Resolución N. ${ }^{\circ} 46$ del 18 de julio de 1942 a la Cooperativa Unión Chiquinquireña de Transportes, y luego ampliadas en la Resolución N. 79 del 5 de agosto del mismo año, se estipuló los precios diferenciales de los tiquetes en coche o en bus. Allí se establece que el viaje de Chiquinquirá a Muzo (principal para el occidente de Boyacá), en auto costaba tres pesos y 30 centavos, mientras que en bus se pagaba dos pesos ${ }^{30}$.

De igual manera la proliferación de leyes y dependencias del transporte modificó la especificidad en las rutas; como ya se había señalado, a principios de la década solo se aludía a la existencia de la Dirección. Sin embargo, durante el periodo comprendido entre 1943 y 1947, el posible desgaste en la actividad a causa de las restricciones comerciales ocasionadas por la Segunda Guerra Mundial y los altos niveles de competitividad, condujo a la asignación de líneas fijas. En efecto, las compañías comenzaron a estipular sus ejes de servicio; incluso algunas se referían a resoluciones emitidas por el ejecutivo en las cuales se precisaba el valor de los tiquetes por carretera, de este modo se buscaba que las empresas mantuvieran igualdad en sus planes tarifarios.

Este fue el caso de Transportes El Lago Limitada, que en su acta de constitución indicaba el itinerario de servicio en torno a la ruta número cuatro planteada por el Ministerio de Obras Públicas en la Resolución N. 46 de 1942, en la que se autorizó a las empresas que podían transitar por el grupo de líneas asignadas a la zona de Tunja (Tunja-Barbosa-Puerto Olaya,

${ }^{30}$ ARB, Fondo Notaría Primera del Circuito de Tunja, 1942. 
Tunja-Ramiriquí-Miraflores, Tunja-Arcabuco-Chiquinquirá y ramales, Duitama-Sogamoso y ramales). Respecto de la última se establecieron los municipios que abarcaba y las dos sociedades que tenían derecho a operar por estos lugares (Expreso Casanare y Transportes El Lago). ${ }^{31}$

Si bien el análisis en torno a los incrementos de las tarifas y a la asignación de rutas en Boyacá debiera considerar las disposición de alrededor de seis zonas de servicio ubicadas en las principales carreteras y centros económicos (Central del Norte, Carare, Tunja y ramales, y las provincias Sugamuxi y Tundama), en el artículo, por cuestiones de extensión, se tratará únicamente la ruta Duitama-Cúcuta que fue la más extensa del departamento y, una de las que ofrecía mayores utilidades en la medida que la capital de Norte de Santander se caracterizaba por ser un espacio de intercambio comercial de mercancías tanto venezolanas como colombianas y su ubicación en la zona fronteriza la hacía paso obligado para Venezuela. Muchos de los pasajeros que viajaban hacia Cúcuta visitaban la ciudad para luego embarcarse en un recorrido de descanso en el país vecino. Asimismo, los distintos municipios comprendidos en esta ruta contaban con agencias de las empresas y concentraban la mayor cantidad de población de la región (Santa Rosa de Viterbo, Belén, Santa Rosita, Málaga, Cerritos, Chitagá, Pamplona); por tanto, eran zonas estratégicas para cargue y descargue de pasajeros.

Otro factor a tener en cuenta en la línea mencionada fue la posición de Duitama, que se proyectó desde la primera mitad del siglo XX como centro industrial y comercial de la región. En principio con algunas fábricas manufactureras de carácter artesanal, luego se establecieron compañías nacionales como Bavaria S. A., Sofasa, algunas de las principales empresas carroceras, y más de 100 talleres de metalmecánica, transformándose en una ciudadela que contaría paulatinamente con servicios como bancos, comunicaciones, bibliotecas, comercializadoras y hospitales ${ }^{32}$. Por tanto, las rutas de servicio ubicadas alrededor de esta ciudad, y de su corredor industrial (comprendiendo Sogamoso y Paz del Río) se dedicaron al transporte de empleados, profesionistas y estudiantes del departamento.

Igualmente Sogamoso fue foco de complejos industriales: Cementos Boyacá, constituida en 1955, cuya planta se localizó a las afueras de esta ciudad, (Nobsa)

31 Archivo Central de Sogamoso (en adelante ACS): Notaría Primera del Circuito Sogamoso, Escritura $\mathrm{N}^{\circ} 982$ del 22 de diciembre de 1945.

32 Archivo Digital Periódico El Tiempo (en adelante ADET), El Tiempo, 2 de enero de 1978, "Reseña histórica. Vertiginoso auge industrial", 6. 
se convirtió en una de las compañías de mayor producción nacional. Para 1965, tras una fase de crisis financiera, la empresa producía diariamente 450 toneladas de cemento comercializadas en el mercado del país, compitiendo con industrias de trayectoria como la Fábrica Samper y Cementos Argos ${ }^{33}$.

De otro lado, la operación de la planta de Acerías Paz del Río y de otras siderúrgicas originó constantes movilizaciones cotidianas de los habitantes de la región. Inclusive antes de la instalación de la compañía en Boyacá, se realizó la "Gran Semana Pro-siderúrgica”, en la cual entidades oficiales y personas del común de todos los municipios (124) del departamento manifestaron a través de ferias, marchas y cruzadas su apoyo a la fundación de la misma, en razón del progreso y el de la economía que generaría ${ }^{34}$.

La empresa era símbolo de independencia económica y transformación social; su objetivo fue la explotación del hierro sin intervención extranjera y la inclusión laboral de los habitantes de los municipios donde se hallaban las vetas. Efectivamente vinculó 5.000 trabajadores, de los cuales 3.800 estaban en Belencito y el resto en Paz del Río, lugares donde se realizaba la explotación de carbón y acero. Además de los obreros, inicialmente la compañía contrató ocho ingenieros encargados de la asistencia técnica, 60 especialistas traídos del extranjero (alemanes, franceses y norteamericanos) y otros 13 ingenieros que provenían de las firmas asociadas. Igualmente, en la construcción y en la instalación de equipos y maquinaria participaron maestros y oficiales de Boyacá, Cundinamarca y Santander, quienes fueron los usuarios más frecuentes de las rutas Duitama-Sogamoso, Sogamoso-Belencito, Sogamoso-Paz del RíoTópaga, así como, de algunas líneas hacia Cúcuta y Bucaramanga ${ }^{35}$.

En suma, las rutas de transporte regional de pasajeros se configuraron alrededor del crecimiento de las actividades económicas principales, es decir, la agricultura, el abastecimiento local de mercados, los sitios de descanso, la riqueza cultural e histórica y, posteriormente, la industria que fue esencial para la ampliación de espacios de servicio.

${ }^{33}$ Para profundizar en este tema se recomienda: González Casas, "Informe de directivo y gerencia de Cementos Boyacá”, Nuevo Boyacá, 24 (Bogotá: Gonzalo Vargas Rubiano, 1965): $12-13$

${ }^{34}$ ADET, El Tiempo. 1947. "De Tunja. Semana Cívica Pro-Siderúrgica de Paz de Río tendrá lugar en fecha próxima”, 17 de agosto, 4.

35 Véase: Chaparro Montaña, Rodrigo, "La ciudad Sorprendida. La Siderúrgica de Acerías Paz del Río y la configuración socio-espacial de Sogamoso”, (Tesis de Licenciatura, Universidad Industrial de Santander, 2013), 68-70, 470. ACS, Acción Cívica. 1953. "Paz del Río una realidad”, núm. 219, 27 de junio, pp. 5-6. 
Más allá de la importancia que tuvo el corredor industrial en cuanto al volumen de usuarios, no se puede soslayar que gran parte de las rutas situadas en ramales (municipios pequeños y de menor número de habitantes) se dedicaron al traslado de la población rural hacia los centros urbanos, en particular los días de mercado, cuando las chivas iban hacia las veredas a determinadas horas y recogían alrededor de las plazas o lugares de abasto a los campesinos, permitiéndoles la carga de mercancías o productos agrícolas.

Junto con las particularidades de cada zona de servicio, en cuanto a utilidad e importancia, se observa que había control por parte de cuatro o cinco compañías de las líneas situadas en los espacios señalados, a las cuales se les otorgaba prácticamente la libertad de tránsito y operatividad. Por ejemplo, en el área comprendida por Tunja y ramales funcionaron tres empresas ( $\mathrm{La}$ Garantía, Busexpreso y Cooperativa Colombiana de transportes) con siete rutas; situación que sugiere un orden interno y una distribución del servicio de transporte. Sin embargo, este fue uno de los principales problemas del sector, en tanto, que revelaba un supuesto monopolio y limitaba el crecimiento de pequeñas empresas que surgían y competían, con quebrantos, con aquellas ya consolidadas.

\section{Sociedades de transporte: devenir y proximidades empresariales}

En Boyacá, la primera compañía, Autobuses Saurer, se constituyó en 1930 y tenía como objeto la movilidad de pasajeros y encomiendas alrededor de la carretera central del Norte. Los cinco socios que la conformaron aportaron, en moneda colombiana, la suma de mil pesos más unidades tipo autobús marca Sauber 3BH. Con estas prestarían el servicio y, a su vez, cancelarían la deuda obtenida con la casa comercial que les había financiado las máquinas. El ideal de la sociedad era tener vehículos de su propiedad para reducir costos y garantizar el suministro de llantas y repuestos como una responsabilidad solidaria de los fundadores, tendencia que asumieron más adelante otras empresas como parte de su organización y funcionamiento ${ }^{36}$.

A partir de Autobuses Saurer, el establecimiento de empresas de transporte de pasajeros empezó a crecer constantemente. En tan solo treinta cinco años se formaron treinta compañías, lo cual demuestra, en primer lugar, lo lucrativo que pudo ser este negocio; en segundo lugar, las posibilidades generadas para aquellos hombres y mujeres con fortunas limitadas y, por último, las facilidades

${ }^{36}$ ARB, Fondo Notaría Segunda del Circuito Centro: Escritura N. ${ }^{\circ} 729$ del 6 de noviembre de 1930, por la cual se constituye Sociedad Cooperativa de Autobuses Saurer. 
de constitución y operatividad. Empero el interés progresivo por la actividad se volvió un problema cuando la competencia excesiva sobrepasó el tamaño del mercado, por cuanto muchas de las sociedades cubrían las mismas zonas, es decir, compartían rutas. De igual manera, el crecimiento poblacional no era suficiente para satisfacer la oferta de unidades y líneas (Figura 2).

Figura 2. Natalidad de las empresas de transporte de pasajeros en Boyacá, 1930-1965

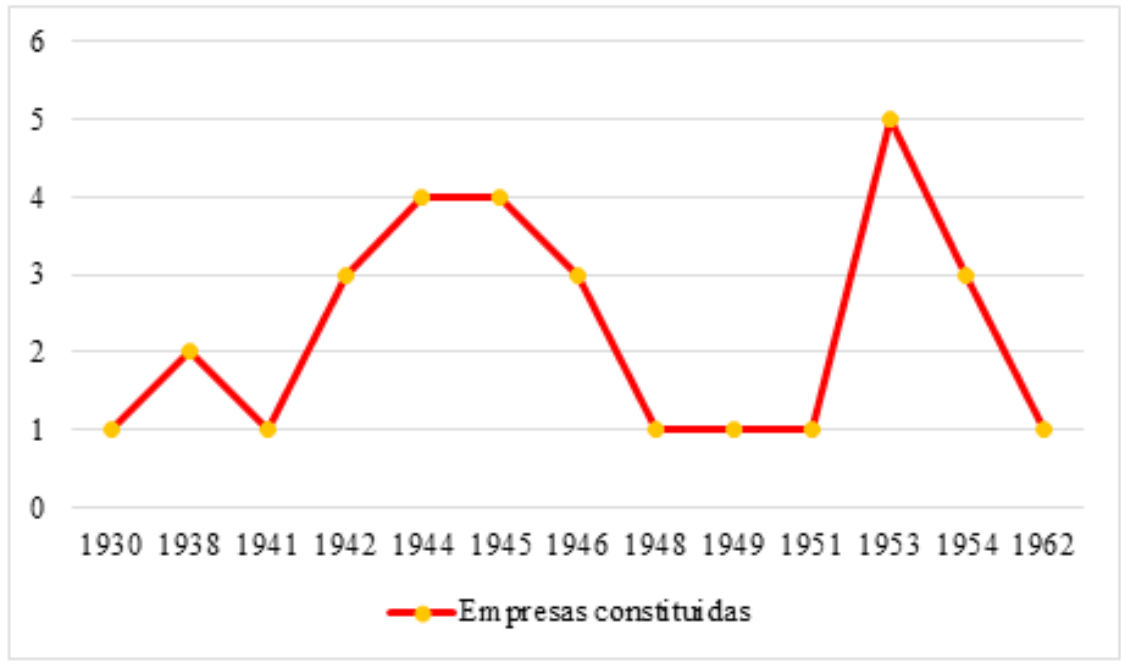

Fuente: elaboración propia con base en fuentes notariales (1930-1965) y Diario Oficial (1942-1960)

En promedio se estiman una o dos compañías establecidas por año; sin embargo, la realidad empresarial del transporte fue distinta; hubo periodos en los que no se constituyó ninguna sociedad, mientras que en otras anualidades se observó una creación relativamente numerosa, particularmente en 1946 y en 1953 se establecieron cuatro y seis empresas respectivamente. Esto respondió a la instauración de políticas e instituciones que regularon y ejercieron mayor control sobre el sector, así como a la apertura de más rutas y zonas de servicio en la década de los cuarenta y principios de los cincuenta;. otro factor fue la conformación de la industria pesada, paralelo al crecimiento del corredor industrial boyacense.

Al fraccionar el periodo estudiado en tres décadas: la primera comprendida entre 1930 a 1940, la segunda, de 1941 hasta 1950, y la tercera, 1950 a 1963 , se evidencian variaciones sustanciales en cuanto a la demografía empresarial 
del transporte ${ }^{37}$, con una creación porcentual de sociedades del 10, 56 y 34 por ciento respectivamente, del total de compañías con escritura notarial (30). De lo anterior se infiere que la mitad se registró en la década de los años cuarenta, motivadas por la exigencia pública institucional de amparo y legalidad otorgada a través de las licencias de funcionamiento (Figura 3).

Figura 3. Fertilidad empresarial del transporte por décadas

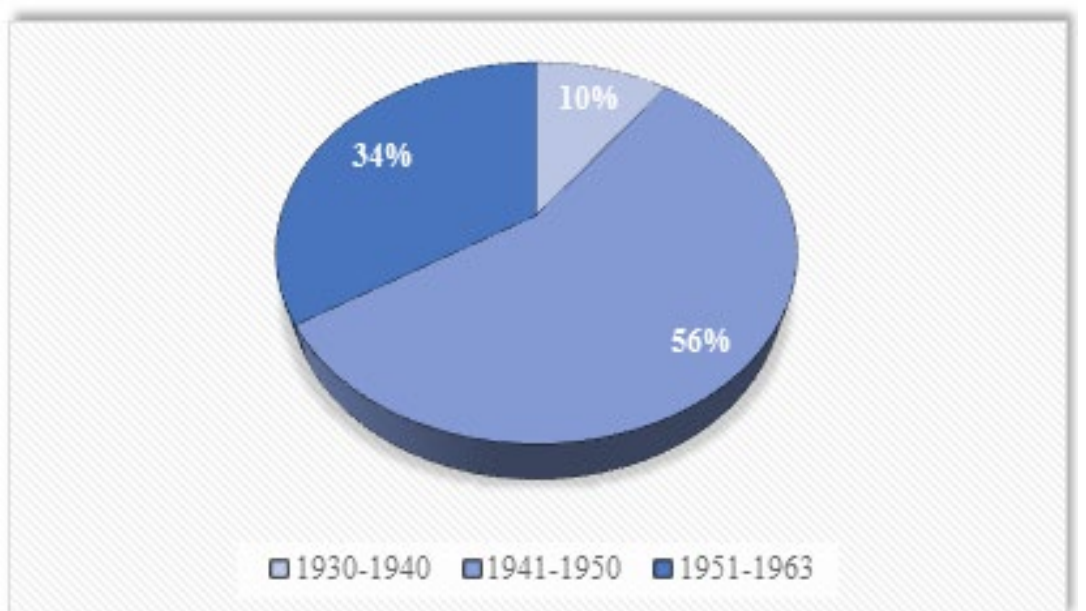

Fuente: elaboración propia con base en fuentes notariales y Diario Oficial (1942-1960)

Las compañías de transporte estudiadas en esta investigación se proyectaban para un lapso promedio de entre dos y diez años. Del total, el seis por ciento suscribía una duración a largo plazo, mientras que el noventa y cuatro por ciento veía más pertinente un menor o un mediano plazo. Su permanencia, en la mayoría de casos, dependía del número de socios y, en especial, del capital inicial de cada una. Las empresas cuyo propósito era operar entre dos a tres años se formaban con haberes sociales que no superaban los seis mil o siete mil pesos colombianos y se fundaban por el interés de entre tres y siete empresarios.

${ }^{37}$ Los términos 'fertilidad' y 'natalidad empresarial' se utilizan con base en los planteamientos de Mario Cerutti, quien aplica el enfoque demográfico para explicar y dar cuenta de la constitución anual, o en determinado periodo, de las compañías vinculadas a distintos sectores económicos de un espacio específico, así como sus variaciones, ritmos y cambios. Véase Mario Cerutti, “Fertilidad empresarial en Monterrey (1885-1930)”, en La economía mexicana en 19 miradas, coord. Daniel Flores Curiel, María Lourdes Treviño Villarreal y Jorge Noel Valero Gil, (México F. F.: Universidad Autónoma de Nuevo León, Porrúa, 2009), 393-427. 
Por ejemplo, las empresas Transportes Boyacá S. A. y Transportes Santander Limitada se caracterizaron, en primer lugar, por constituirse en la década de los cuarenta que se considera como un periodo de inicio y posible fomento del transporte nacional y regional en respuesta a las demandas y a la inversión en vías o carreteras; en segundo lugar, por la vinculación de sus socios con talleres de repuestos y ventas de gasolina que les servían para reducir costos en combustibles y mantenimiento; $\mathrm{Y}$, en tercer lugar, por tener un capital inicial semejante, con la diferencia de que la compañía Boyacá S.A. dividía los veintisiete mil pesos en noventa acciones de valor nominal, mientras que la sociedad Santander atribuía treinta mil pesos a maquinaria (buses) y objetos de oficina ${ }^{38}$.

En cambio, las sociedades que aspiraban a prolongar su funcionamiento a más de cinco años usualmente iniciaban con seis, diez o más socios, quienes, a través de sus respectivos aportes, acumulaban montos superiores a ocho mil pesos, y algunas sumaron capitales mayores de treinta mil. Por ende, estas apuntaban a incrementar sus fondos, expandir sus focos de servicio y comercializar las acciones o las partes que las componían (Figura 4).

Las empresas se constituyeron con haberes sociales que oscilaron entre los $\$ 500$ y los $\$ 90.000$; el aporte inicial en cada una dependía de varios elementos: si el capital estaba representado por el avalúo de los vehículos de los empresarios, o si se pagaba en efectivo. Por lo general, los montos que no superaban los tres mil o cuatro mil pesos correspondían a dinero en efectivo dividido en partes iguales entre los socios, el cual se utilizaba para los insumos de oficinas y los periodos de crisis financiera. En estas compañías los vehículos eran propiedad de cada transportista, a quien se responsabilizaba de su mantenimiento y revisión periódica.

La actividad transportadora de pasajeros recaudó, durante el periodo estudiado, un total aproximado de $\$ 506.230$, suma que, al compararse con otros rubros como los de la industria pesada y la manufacturera, podría verse como una inversión poco significativa, pero era de gran importancia para el entramado productivo local, en tanto la fuente de capital y el objetivo social de la misma permitieron la estabilidad de la economía regional a través del vínculo demográfico y mercantil con espacios interdepartamentales.

${ }^{38}$ ARB: Fondo Notaría Primera del Circuito Centro, Escritura N. ${ }^{\circ} 933$ del 1. ${ }^{\circ}$ de octubre de 1945, y Notaría Segunda del circuito de Santa Rosa (en adelante NSSR), Escritura N. ${ }^{\circ} 237$ del 11 de mayo de 1948. 
Figura 4. Variación de capitales y número de socios según tiempo de proyección empresarial

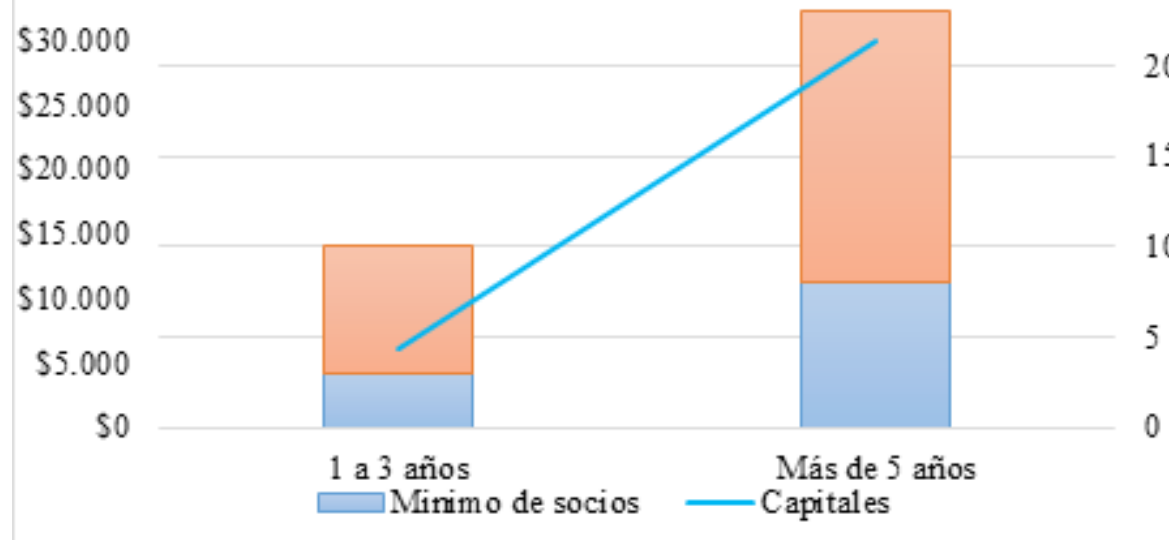

Fuente: elaboración propia con base en fuente notarial (1930-1965)

$\mathrm{Al}$ analizar la capitalización del sector en las tres décadas mencionadas, se aprecia que los años treinta sólo representaron el dos por ciento del capital empresarial, y las décadas de los cuarenta y cincuenta, el 58 y 40 por ciento respectivamente. Si bien la primera cifra equivalió a la mitad de la inversión, la segunda agrupó la participación de tan sólo 9 compañías entre las cuales se encontraban tres consideradas de envergadura nacional; es decir, que fueron, y son, empresas cuyo haber social facilitó la asignación de zonas de servicio estratégicas para su crecimiento. Esto no implica que durante los años cuarenta no se hayan consolidado sociedades de dicha magnitud; sin embargo, de las 16 conformadas en ese periodo, el 80 por ciento fueron compañías de carácter intermunicipal que no lograron competir ante las demás (Figura 5).

Usualmente las empresas constituían diferentes fondos parala organización de sus finanzas (pasivos, activos y beneficios). Al llamado de reserva legal se destinaba entre el 10 y 20 por ciento de las utilidades netas anuales o semestrales que resultaran del balance general, y se utilizaba para el pago de cesantías y sueldos de empleados, la cancelación de impuestos y la compra de unidades para renovar su parque automotor. Las empresas Trans Bolívar Ltda. y Transportes Boyacá S.A. utilizaron esta disposición para expedir o colocar a la venta acciones de preferencia a suscriptores que fueran transportistas. Con esto no sólo incrementaban su haber social, sino que valorizaban sus 
acciones, es decir, adquirían mayor capacidad tributaria y más facilidades para la asignación de rutas y la matrícula de nuevas unidades ${ }^{39}$.

Figura 5. Capital empresarial y diferencias de inversión en el transporte de pasajeros

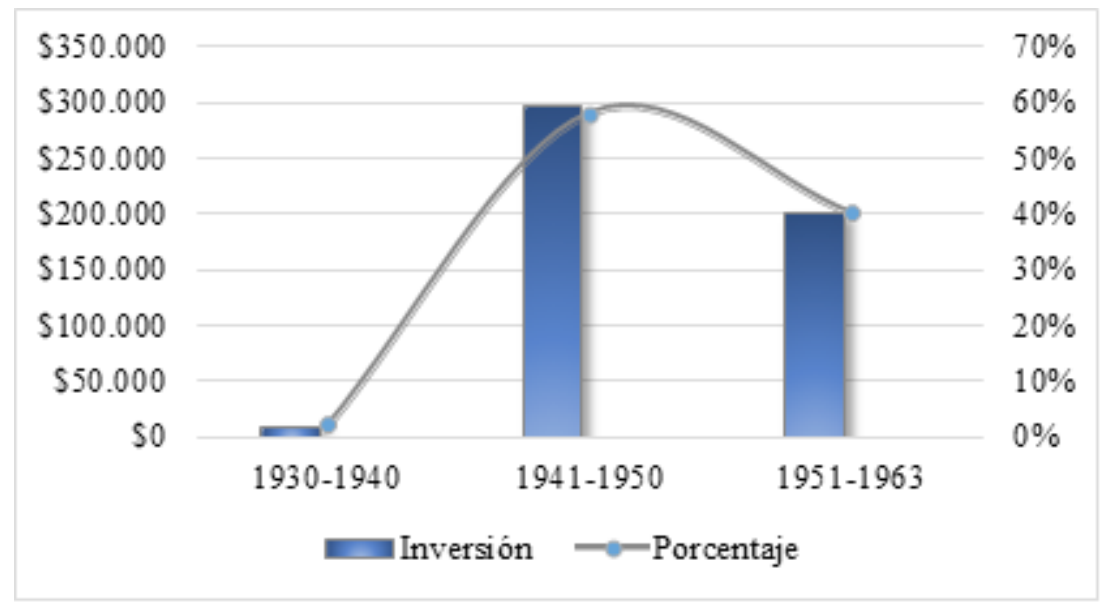

Fuente: elaboración propia con base en fuente notarial (1930-1965).

De igual forma, se extraía, del producido bruto de cada máquina, un 10 por ciento para el fondo de garantía individual, los gastos de administración y el fondo común o social. Los porcentajes correspondientes a cada sección, así como su empleo respectivo, dependían de los estatutos de cada compañía. Sin embargo, se encuentra que el primero se disponía para robos o pérdidas de carga transportada, perjuicios a terceros y pago de obligaciones contraídas por los socios con entidades financieras. El segundo se ocupaba para los sueldos de gerente, tesorero y revisor fiscal, así como arrendamientos, gastos de oficina (enseres, papelería, servicios), expedición de planillas y tiquetes ante las autoridades gubernamentales. Finalmente, el fondo común era un sistema de ahorro que tenían los socios para momentos de pérdidas o bajas de capital ${ }^{40}$.

${ }^{39}$ Véase respectivamente Notaría Primera del Circuito de Santa Rosa (en adelante NPSR), Escritura N. ${ }^{\circ} 661$ del 30 de septiembre de 1943; ARB: Notaría primera del Circuito Centro, Escritura N. ${ }^{\circ} 933$ del 10 de octubre de 1945.

${ }^{40}$ Véase NSSR, Escritura N. ${ }^{\circ} 788$ del 13 de noviembre de 1946, en la que se constituye Rápido Duitama Ltda. NPSR, Escritura N. ${ }^{\circ} 107$ del 12 de febrero de 1946 por la cual se solicita prórroga a la Sociedad Automóviles La Colombiana. Robles, L., Código de comercio de la República de Colombia, Capítulo 1, Sección Sexta, Art. 539, p. 95. 
Las modificaciones entre una y otra compañía a nivel administrativo y financiero obedecieron a las transiciones que tuvo la actividad y al orden empresarial del transporte, es decir, en los primeros años desde su fundación las sociedades regionales tuvieron un carácter más empírico y colectivo, pues el estatuto interno de las empresas solo exigía algunas menciones sobre capital, administración y contabilidad o balances generales de inventario. Sin embargo, con la reglamentación de 1945, el Estado exigió la constitución de, al menos, un fondo de reserva; obligó a las compañías a asegurar sus vehículos y a correr con más gastos de inscripción y matrícula de los mismos, y exigió informes más detallados en cuanto a los activos, bienes inmuebles, producido mensual evidenciado en tiquetes y costos de viajes, gastos de oficina, agencias e insumos requeridos para el mantenimiento de las máquinas.

\section{Consideraciones finales}

La formación de las empresas de transporte y la ampliación de las rutas estuvieron vinculadas al proceso de transición de una economía agraria a una industrial, así como a la migración campo-ciudad. En Boyacá se observa que las compañías constituidas durante la década de los treinta se establecieron para servir la línea Bogotá-Tunja-Cúcuta. Los centros de movilidad correspondían a las ciudades que concentraron la población urbana de dentro y fuera del departamento, y los espacios de trasbordo o agencias intermedias se ubicaron en los municipios con mayor número de habitantes, como Paipa, Paz del Río, Santa Rosa, y Belén. Después de los años cuarenta las empresas extendieron sus rutas hacia los ramales y vías secundarias o transversales (camino al Carare, Progreso y occidente); sin embargo, el funcionamiento y el servicio de las mismas se orientaron a las jurisdicciones principales.

La implementación del transporte de pasajeros mostró la importancia del espacio conformado por el corredor comercial e industrial existente entre Boyacá, los Santanderes, Bogotá y, posteriormente, los Llanos orientales, donde se concentraron algunas de las empresas cementeras, siderúrgicas, metalmecánicas y de servicios más relevantes del país.

Si bien la vinculación de Boyacá a este espacio productivo regional le permitió intercambios de productos agrícolas e inclusión en la política económica del país, que beneficiaron las zonas colindantes con el centro administrativo e institucional consolidado en su capital Bogotá. También lo convirtió en un foco atractivo para establecer sedes de algunas industrias constituidas en otros departamentos, cuyo crecimiento empresarial dependía 
de la ubicación geoestratégica de sus bienes. Lo cual da cuenta de procesos y dinámicas económicas locales caracterizadas por un entramado productivo que se dedicó a diferentes actividades agropecuarias, empresariales, artesanales e industriales, en las que la transición de una economía rural hacia otra primordialmente urbana configuró la forma como se desarrollaron y relacionaron dichas actividades.

Por consiguiente, queda a un lado la hipótesis que considera a Boyacá como un espacio dependiente y subestimado por la economía capitalina; en cambio, se plantea que el tejido regional boyacense amplió y facilitó las dinámicas propias del altiplano en tanto lo abasteció de insumos y cultivos; configuró una red de transporte que incluyó las demandas de mercados y usuarios no solo de Bogotá, sino de Bucaramanga, Cúcuta y jurisdicciones próximas a Puerto Berrío y, finalmente dotó de fuerza laboral a fábricas, compañías u oficinas situadas en su interior.

A su vez, se refuta la consideración de atraso, bajo la cual se ha catalogado a la dinámica económica boyacense, desde la historiografía partidaria de las teorías de modernización u otras versiones ortodoxas de la economía del desarrollo, en las que se identifica e iguala dicha modernización con el crecimiento de la industria. En la presente investigación se expone que, más allá de las industrias instaladas en el departamento, el comportamiento empresarial tanto en el sector servicios (transporte, bancos) como en la agricultura y el comercio es un factor decisivo para los cambios económicos regionales. De modo tal que los negocios familiares, con predominio de capitales oriundos de la región, y que resultaban de interés para personas procedentes de la misma, fueron fundamentales para la configuración y los vínculos entre las empresas y diversos sectores.

El comportamiento empresarial y el devenir del sector condicionaron, tal como se señaló en la hipótesis, la evolución y los cambios dentro de las compañías de transporte, que, dentro de su natalidad empresarial, revelan un proceso cronológico en relación al número de sociedades creadas por año o periodo, pero dialéctico en la forma de vincular su capital y en el uso de tácticas para superar las limitantes económicas e históricas que se originaron a consecuencia de la fuerte competencia y el desorden interno de la actividad. En otros términos, las empresas invirtieron sus haberes según el radio de operación (urbano, intermunicipal o interregional), el tipo de sociedad que legitimaba y determinaba su registro, la proyección que hacían del negocio 
acorde al número de unidades, el total de acciones y el resultado reflejado en la capacidad financiera de su fondo de reserva.

De otra parte, las compañías con mayores haberes sociales, consideradas de envergadura nacional por el control que ejercían en rutas hacia capitales de otros departamentos, se unificaron o quebraron a sociedades cuya zona de servicio se redujo a dos o tres líneas como máximo. Este proceso de crecimiento y bancarrota de unas u otras se derivó de factores determinantes en su permanencia: por un lado, los vínculos y la ocupación de cargos políticos facilitaban a los empresarios disponer, cambiar e incluso instaurar nuevas normativas que beneficiaran sus ganancias, asimismo les permitió sobornar a autoridades locales encargadas de regular el flujo de buses, tiempos de salida y espacios de parada o ascenso de pasajeros; por otro, la capacidad transportadora que se asignaba dependió del crecimiento, del capital y de la utilidad empresarial, así que, entre más número de unidades y mejores balances financieros, eran más amplias las zonas de servicio.

\section{Referencias bibliográficas}

\section{Fuentes primarias}

\section{Manuscritas}

AGNC Archivo General de la Nación Colombia.

ARB Archivo Regional de Boyacá, Fondo Notarías Primera y Segunda del circuito Centro.

ACS Archivo Central de Sogamoso, Fondo Notaría Primera del circuito Sogamoso.

NSSR Notaría Segunda del circuito de Santa Rosa.

\section{Impresas}

\section{Periódicas}

Diario Oficial, 1930-1965.

El Boyacense, 1930-1950.

Acción Cívica, 1953.

El Vigía, 1930.

\section{Digitales}

ADEL Archivo digital periódico El Tiempo, 1934, 1939, 1958-1962, 1974.

\section{Fuentes secundarias}

Acemoglou, Daron, Simon Johnson y James Robinson. “Institutions as the Fundamental Cause of Long-Run Growth". The National Bureau of Economic Research, ก.․ 10.481 (2004): 1-111. 
Acuña Rodríguez, Olga Yaneth. "Aproximaciones a la historia empresarial de Boyacá (Colombia), 1900-1930”. Historielo: Revista de Historia Regional y Local vol. 6, núm. 12 (Unal, 2014): 171-202.

Barreto Bernal, Patricia Carolina. "Conformación del empresariado del sector siderúrgico y su papel en los procesos de modernización social, económica y administrativa, en el corredor industrial de Boyacá, 1960-1990”. Tesis doctoral, Universidad Eafit, Medellín, 2014.

Cerutti, Mario. "Crisis y reconvención del tejido productivo en un espacio regional del norte de México: La Laguna (1875-1975)”, Revista Investigaciones de Historia Económica, 10 (España: Asociación Española de Historia Económica, 2008): 97-128.

Cerutti, Mario. “Fertilidad empresarial en Monterrey (1885-1930)”. En Laeconomía mexicana en 19 miradas. coord. Daniel Flores Curiel, María Lourdes Treviño Villarreal y Jorge Noel Valero Gil, 393-427. México D. F.:: Universidad Autónoma de Nuevo León, Porrúa, 2009.

Chaparro Montaña, Rodrigo. "La ciudad sorprendida. La Siderúrgica de Acerías Paz del Río y la configuración socio-espacial de Sogamoso”. Tesis de Licenciatura, Universidad Industrial de Santander, 2013.

Fals Borda, Orlando. El hombre y la tierra en Boyacá: bases sociológicas e históricas para una reforma agraria. Bogotá: Universidad Pedagógica y Tecnológica de Colombia, 2006.

Garza Villarreal, Gustavo. “La revolución macroeconómica del sector servicios”. En La economía mexicana en 19 miradas, coord. Daniel Flores Curiel, María Lourdes Treviño Villarreal y Jorge Noel Valero Gil, 361-391. México D. F.: Universidad Autónoma de Nuevo León, Porrúa, 2009.

Kalmanovitz, Salomón. Lasinstituciones y el desarrollo económico en Colombia. Bogotá: Editorial Norma, 2001.

Maillat, Denis. "Sistemas productivos locales y entornos innovadores". En Redes de empresas y desarrollo local: competencia y cooperación en los sistemas productivos locales, 75-90. Paris, Francia: OCDE, 1999.

Marichal, Carlos "Introducción”, en Historia de las grandes empresas en México (1850-1950), comp. Mario Cerutti y Carlos Marichal (México: FCE, 1997), 9-38.

Meisel Roca, Adolfo. "Los estudios sobre historia económica de Colombia a partir de 1990: principales temáticas y aportes”. Cuadernos de historia económica y empresarial, núm.13 (Bogotá, Banco de la República, 2005): 4-42.

North, Douglas. Instituciones, cambio institucional y desempeño económico. México: Fondo de Cultura Económica, 1995.

Ocampo, José Antonio. "La consolidación del capitalismo moderno”. En Historia económica de Colombia, comp. José Antonio Ocampo. Bogotá: Siglo XXI Editores, 1987.

Prince, David y Alasdair Blair. The Changing Geography of the Service Sector. Londres: Belhaven Press, 1989. 
Ramírez, María Teresa y Álvaro, Pachón. La infraestructura del transporte en Colombia durante el siglo XX. Bogotá: Fondo de Cultura Económica, 2006.

Ramírez, María Teresa. "Efectos de eslabonamiento de la infraestructura de transporte sobre la economía colombiana 1900-1950". En Economía colombiana del siglo XX: un análisis cuantitativo, comp. James Robinson y Miguel Urrutia, 383-402. Bogotá: Fondo de Cultura Económica, 2007.

Robles, Luis. Código de comercio de la República de Colombia. Bogotá: Imprenta de la Luz, 1899.

Salehi Esfahani, Hadi y María Teresa Ramírez, "Intitutions, Infrastructure and Economic Growth", Forthcoming in Journal of Development Economics, 70 (IISES, 2003): 443-477.

Schumpeter, Joseph. Teoría del desenvolvimiento económico. México: Fondo de Cultura Económica, segunda edición, 1997.

Villarreal, Sebastián y Darío Ortiz, "Transporte y mercado interno en Colombia: una contribución a un debate hasta ahora desconocido, 1928-1950". Tiempo y Economía, vol.3, núm.1 (Universidad Jorge Tadeo Lozano, 2016): 83-107. 